Altai State University

Acta 3iologica Gibirica

Journal of Biology

Founded in 2015

ISSN 2412-1908

Acta Biologica Sibirica, 2017, 3(4), 123-126

\title{
New data on distribution of Cypripedium macranthon sw. on the territory of Altai krai
}

\author{
S.V. Vazhov, G.G. Rusanov, V.M. Vazhov, R.F. Bachtin \\ The Shukshin Altai State Humanities Pedagogical University, Biysk \\ Email:vazhov49@mail.ru
}

The Family Orchidaceae Juss. -occupies an important place among the plants, which were highlighted related to their biology and ecology. The total number of species of the family in the Altai region - 27 (ruberoidny -13, rhizomatous - 14), 10 species of orchids are rare and protected. Among the many flowering plants highlights one of the most beautiful and the most noticeable because of its large flowers Orchid - lady's slipper large-flowered Cypripedium (Cypripedium macranthon Sw.). This species is rare and listed in the regional Red book, as residential landscape areas suffers from collecting in bouquets and digging out the gardeners for the introduction into the culture. Exterminated Orchid in the procurement of herbal raw materials in traditional medicine. The Shoe form a plurality of decorative forms that is of interest to collectors of plants, promotes the collection and implementation in connection with the market demand. Increasing anthropogenic load on the territory of the region, which also adversely affects the number and state of coenopopulations of $C$. macranthon Sw. For the Altai territory, the modern updated data on the habitat of the Orchid. Four previously unknown local populations of $C$. macranthon Sw. it is noted in the upper basin of the river Angara in the virgin area.

Key words: Cypripedium macranthon; habitat; Tselinnyy rayon

\section{Новые данные о распространении Cypripedium macranthon sw. на территории Алтайского края}

\author{
С.В. Важов, Г.Г. Русанов, В.М. Важов, Р.Ф. Бахтин \\ Алтайский государственный гуманитарно-педагогический \\ университет имени В.М. Шукшина, г. Бийск \\ Email: vazhov49@mail.ru
}

\footnotetext{
Семейство Orchidaceae Juss. -занимает важное место среди растений, которым уделено особое внимание, связанное с их биологией и экологией. Общее число видов семейства на территории Алтайского края - 27 (тубероидные -13, корневищные - 14), 10 видов орхидных являются редкими и охраняются. Среди многих цветущих растений особо выделяется одна из красивейших и наиболее заметных из-за своих крупных цветков орхидея - Венерин башмачок крупноцветковый (Cypripedium macranthon Sw.). Данный вид является редким и занесен в региональную Красную книгу, так как в селитебных ландшафтах ареалов страдает от сбора в букеты и выкапывания садоводами для введения в культуру. Истребляется орхидея при заготовке растительного сырья в народной медицине. Башмачок формирует множество высокодекоративных форм, что вызывает интерес у
} 
коллекционеров растений, способствует сбору и реализации в связи со спросом на рынке. Возрастает антропогенная нагрузка на территорию региона, что также отрицательно сказывается на численности и состоянии ценопопуляций C. macranthon Sw. Для территории Алтайского края уточнены современные данные о местообитаниях орхидеи. Четыре ранее неизвестных локальных популяции C. macranthon Sw. отмечены в верховье бассейна реки Ангуреп в Целинном районе.

Ключевые слова:башмачок крупноцветковый; местообитание; Целинный район

Высокое видовое разнообразие растений и животных предопределило включение части территории Алтайского края в Алтае-Саянский экорегион в числе 200 очагов биологического разнообразия мира (Силантьева, 2017). Однако Алтайский край принадлежит к числу самых развитых сельскохозяйственных регионов России, кроме того, на его территории активно расширяется туристско-рекреационная сфера, что негативно сказывается на биоразнообразии. За многие годы деятельность человека привела к преобразованию исходной флоры региона в антропогенно-трансформированную, включающую синантропные фракции. Несмотря на это, даже в таких условиях природа края сохраняет богатое растительное разнообразие. Флора Алтайского края представлена более 2100 видами высших сосудистых растений, в том числе - свыше 1800 аборигенных и 300 адвентивных, около 400 видов мхов, около 700 видов лишайников (Государственный доклад..., 2013).

Семейство Orchidaceae Juss. - одно из крупнейших среди покрытосеменных и занимает заслуженное место среди растений, которым уделено особое внимание, связанное с их биологией и экологией (Сулименкина, 2011, 2012; Важова и др., 2012; Аверьянов, 2015).

Общее число видов семейства Orchidaceae Juss. на территории Алтайского края - 27 (тубероидные -13, корневищные - 14), 10 видов орхидных внесены в Красные книги разных уровней (Сулименкина и др., 2015).

Среди многих цветущих растений Алтая особо выделяется одна из красивейших и наиболее заметных из-за своих крупных цветков орхидея - Венерин башмачок крупноцветковый (Cypripedium macranthon Sw.). Opхидея является охраняемой. Статус 36. Редкий по всему ареалу вид (Красная книга..., 2006; Силантьева, 2016).

C. macranthon Sw. в селитебных ландшафтах локальных ареалов особенно страдает от сбора в букеты и выкапывания садоводами для введения в культуру. Истребляется орхидея также при заготовке растительного сырья как эффективный объект народной медицины для лечения нервных, психических и других заболеваний. Башмачок крупноцветковый формирует декоративные формы, что вызывает интерес у коллекционеров растений, способствует сбору и нелегальной продаже дикорастущих орхидей (Важова, 2001, 2003). В связи с этим, становятся все более актуальными вопросы изучения и охраны редких видов семейства Orchidaceae Juss., в частности - C. macranthon Sw. (рис. 1).

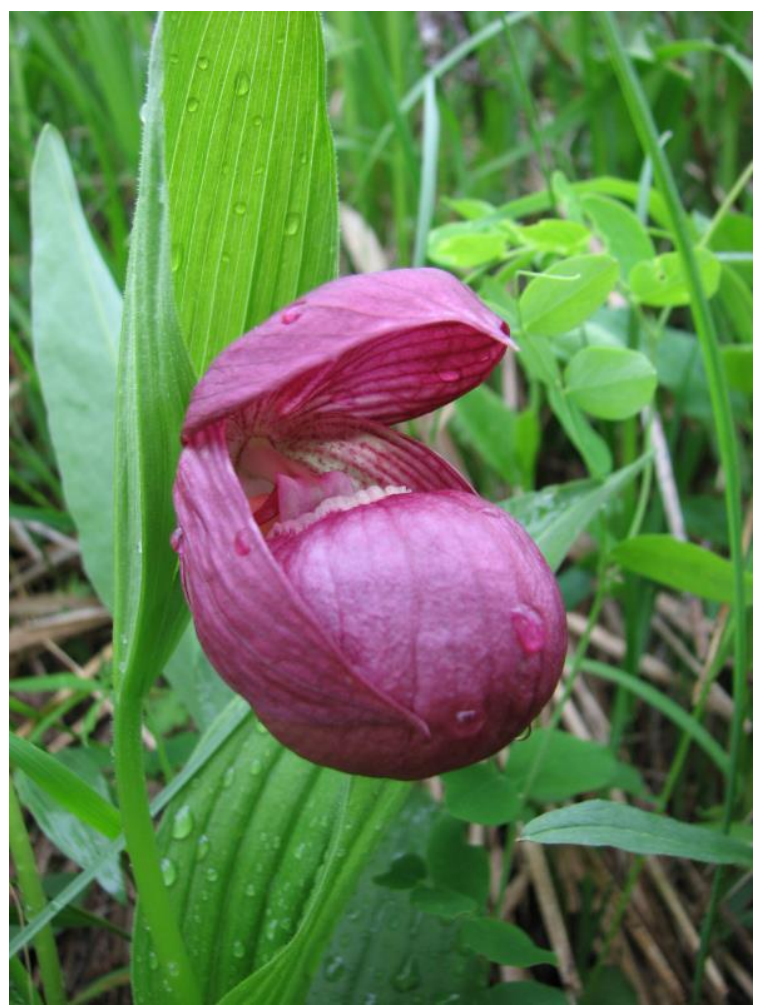

Рис. 1. Венерин башмачок крупноцветковый. Фото С.В. Важова 
Цель настоящей работы - дополнить современные данные о местообитаниях C. macranthon Sw. в лесостепной зоне Алтайского края.

В основу работы положены методы популяционного мониторинга редких и исчезающих видов растений (Быченко, 2008), методы полевых экологических исследований (Методы..., 2014), а также результаты полевых экспедиций авторов.

Для территории Алтайского края уточнены современные сведения о местообитаниях C. macranthon Sw. Четыре ранее неизвестных локальных популяции C. macranthon Sw. отмечены нами в июне 2016 г. в лесостепи Алтайского края в верховье бассейна реки Ангуреп (окрестности с. Овсянниково Целинного района). Информация о данных популяциях башмачка крупноцветкового отсутствует во втором издании Красной книги... (2006), где на стр. 151 обозначено 21 местонахождение C. macranthon Sw. в 13 муниципальных районах края с общей численностью 5-10 тыс. экз. Нет данных о найденных нами популяциях C. macranthon Sw. и в последнем, третьем издании Красной книги... (2016). Хотя количество муниципальных районов, где произрастает C. macranthon Sw., за прошедшие 10 лет после выхода в свет второго издания Красной книги возросло до 19, соответственно, увеличилось и число местонахождений орхидеи - до 38 (стр. 148).

Характеристика местообитаний C. macranthon Sw. в верховье бассейна реки Ангуреп:

1. 5300'39,2" с.ш.; 8602'28,8" в.д. Абсолютная высота 327 м. Днище лога, 6 экз., цветение (10.06. 2016 г.).

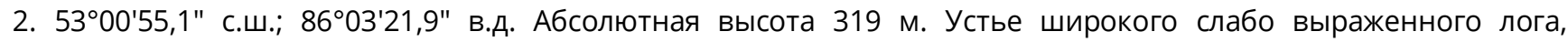
открывающегося справа в долину речки Гришиха, 10 экз., цветение (13.06. 2016 г.).

3. 5300'48,6" с.ш.; 8604'40,9" в.д. Абсолютная высота 315 м. Низовье ручья Веселый - левого притока речки Гришиха, 30 экз., цветение (13.06. 2016 г.).

4. 5249'07,3" с.ш.; 8604'45,7" в.д. Абсолютная высота 360 м. Исток речки Камышенка, которая, сливаясь в с. Овсянниково с речкой Дресвянка, дает начало р. Ангуреп. Склон лога северо-западной экспозиции в $1750 \mathrm{~m} \mathrm{k}$ северо-западу от вершины сопки Карабинская, 6 экз., отцветание (18.06. 2016 г.).

В третьем издании Красной книги... (2016) сказано, что на территории Алтайского края известно свыше 35 местообитаний C. macranthon Sw., а численность отдельных популяций составляет от 20-30 экз. до нескольких тысяч (стр. 149). Самые крупные популяции в крае известны в заказнике «Кислухинский» - каждая до 60-80/100 м² одновременно цветущих особей. Состояние отдельных популяций в труднодоступных местах края стабильное. В Алтайском крае C. macranthon Sw. охраняется на 10 особо охраняемых природных территориях разных категорий (Красная книга..., 2016). В 2016 г. в заказниках «Кислухинский» и «Касмалинский» заложены мониторинговые площадки для наблюдения за состоянием популяций и охраной C. macranthon Sw., а также других орхидей (Силантьева, 2017).

Таким образом, новая информация о местообитаниях C. macranthon Sw. в разных ландшафтных условиях на территории Целинного района Алтайского края позволит дополнить данные о распространении и численности популяций башмачка крупноцветкового с целью совершенствования мер его охраны в лесостепной части региона.

\section{References}

Averianov, L.V. (2015). Ugasaniye aborigennykh flor i missiya botanicheskikh sadov. Okhrana i kultivirovaniye orkhidey. Proceed. Int. Sc. Conf. Minsk: A.N. Varaksin (in Russian).

Bychenko, T.M. (2008). Metody populyatsionnogo monitoringa redkikh i ischezayushchikh vidov rasteniy Pribaykalia: uchebnoye posobiye. Irkutsk: Irkutsk State Pedagogical Institute Press (in Russian).

Gosudarstvennyy doklad "O sostoyanii i ob okhrane okruzhayushchey sredy v Altayskom kraye v 2012 godu" (2013). Barnaul (in Russian).

Krasnaya kniga Altayskogo kraya. (2006). Redkiye i nakhodyashchiyesya pod ugrozoy ischeznoveniya vidy rasteniy. Barnaul: OAO IPP Altay (in Russian).

Krasnaya kniga Altayskogo kraya. (2016). Tom 1. Redkiye i nakhodyashchiyesya pod ugrozoy ischeznoveniya vidy rasteniy $i$ gribov. Barnaul: Altai State University Press (in Russian).

Metody polevykh ekologicheskikh issledovaniy. O.N. Artayev. D.I. Bashmakov. O.V. Bezina, A.B. Ruchin (Eds.). Saransk: Mordovian University Press (in Russian).

Silantyeva, M.M. (2016). Orchidaceae Juss. - Orkhidnyye. Cypripedium macranthon Sw. - Bashmachok krupnotsvetkovyy (pp. 148-149). In: Krasnaya kniga Altayskogo kraya. Redkiye i nakhodyashchiyesya pod ugrozoy ischeznoveniya vidy rasteniy i gribov. Barnaul: Altai State University Press (in Russian).

Silantyeva, M.M., Terekhina, T.A., Speranskaya, N.Yu., Ovcharova, N.V. (2017). Rol OOPT regiona v sokhranenii vidov rasteniy i gribov. zanesennykh v Krasnyye knigi Rossiyskoy Federatsii i Altayskogo kraya. Rol Altayskogo kraya $v$ ekologicheskom karkase Rossiyskoy Federatsii. Procced. Sc. Conf. Barnaul: Tipografiya upravleniya delami Pravitelstva Altayskogo kraya (in Russian).

Sulimenkina, O.Yu. (2011). Vidovoy sostav. rasprostraneniye i okhrana tuberoidnykh orkhidnykh v Altayskom kraye. Izvestiya Altayskogo gosudarstvennogo universiteta, 3/1 (71), 44-47 (in Russian).

Sulimenkina, O.Yu. (2012). Tuberoidnyye vidy orkhidnykh (Orchidaceae) Altayskogo kraya (sostav. ekologo-biologicheskiye osobennosti. problemy okhrany). Thesis of Doctoral Dissertation. Biysk (in Russian). 
Sulimenkina, O.Yu., Vazhov, S.V., Vazhov, V.M. (2015). Redkiye vidy semeystva Orchidaceae Juss. na Altaye. Mezhdunarodnyy zhurnal prikladnykh i fundamentalnykh issledovaniy, 10 (1), 172-173 (in Russian).

Vazhova, T.I. (2001). Redkiye i ischezayushchiye rasteniya Prirechnogo biyskogo bora. Flora i rastitelnost Sibiri i Dalnego Vostoka. Proceed. III All-Russian Conf. Krasnoyarsk (in Russian).

Vazhova, T.I. (2003). Osobennosti prirodnoy flory Biyska. Voprosy prirodopolzovaniya i metodicheskiye aspekty ikh izucheniya: sb. nauch. i metod. statey. "Biyskiy pedagogicheskiy universitet imeni V.M. Shukshina". Biysk, 25-31 (in Russian).

Vazhova, T.I., Chernykh, O.A., Sulimenkina, O.Yu. (2012). Orkhidei g. Biyska Altayskogo kraya. Altay: ekologiya i prirodopolzovaniye. Proceed. XI Russian-Mongolian Sc. Conf. "Altayskaya gosudarstvennaya akademiya obrazovaniya imeni V.M. Shukshina" (in Russian).

\section{Citation:}

Vazhov, S.V., Rusanov, G.G., Vazhov, V.M., Bachtin, R.F. (2017). New data on distribution of Cypripedium macranthon Sw. on the territory of Altai Krai. Acta Biologica Sibirica, 3 (4), 123-126.

Submitted: 18.08.2017. Accepted: 12.10.2017

crossref http://dx.doi.org/10.14258/abs.v3i4.3638

(C) 2017 by the authors. Submitted for possible open access publication under the terms and conditions of the Creative Commons Attribution (CC BY) license (http://creativecommons.org/licenses/by/4.0/). 